2019

\title{
Taking Multiple Regression Analysis to Task: A Review of Mindware: Tools for Smart Thinking, by Richard Nisbett (2015)
}

Jason Makansi

Pearl Street Inc., jmakansi@pearlstreetinc.com

Follow this and additional works at: https://digitalcommons.usf.edu/numeracy

Part of the Multivariate Analysis Commons, Other Mathematics Commons, Quantitative Psychology Commons, and the Statistical Methodology Commons

\section{Recommended Citation}

Makansi, Jason. "Taking Multiple Regression Analysis to Task: A Review of Mindware: Tools for Smart Thinking, by Richard Nisbett (2015)." Numeracy 12, Iss. 2 (2019): Article 17. DOI: https://doi.org/10.5038/ 1936-4660.12.2.17 


\title{
Taking Multiple Regression Analysis to Task: A Review of Mindware: Tools for Smart Thinking, by Richard Nisbett (2015)
}

\author{
Abstract \\ Richard Nisbett. 2015. Mindware: Tools for Smart Thinking.(New York, NY: Farrar, Strauss, and Giroux). \\ 336 pp. ISBN: 9780374536244 \\ Nisbett, a psychologist, may not achieve his stated goal of teaching readers to "effortlessly" extend their \\ common sense when it comes to quantitative analysis applied to everyday issues, but his critique of \\ multiple regression analysis (MRA) in the middle chapters of Mindware is worth attention from, and \\ contemplation by, the QL/QR and Numeracy community. While in at least one other source, Nisbett's \\ critique has been called a "crusade" against MRA, what he really advocates is that it not be used as a \\ substitute for actual experiments. \\ Keywords \\ multiple regression analysis, quantitative literacy, critical thinking, psychology, epistemology, correlation, \\ causation \\ Creative Commons License

\section{(c) (i) (8)} \\ This work is licensed under a Creative Commons Attribution-Noncommercial 4.0 License

\section{Cover Page Footnote} \\ Jason Makansi, a member of the National Numeracy Network, is the author of the award-winning Painting \\ By Numbers: How to Sharpen Your BS Detector and Smoke Out the Experts. He earned his BS in Chemical \\ Engineering from Columbia University and runs an independent consulting firm that specializes in \\ technology deployment for the electricity industry. He has published five professional books, hundreds of \\ articles in academic and professional publications, one novel, and numerous short stories.
}


What else can be said about Mindware: Tools for Smart Thinking after reading the top blurb on the back flap of the book's jacket? Malcolm Gladwell writes, "The most influential thinker, in my life, has been the psychologist Richard Nisbett. He basically gave me my view of the world."

Gladwell has authored some of the most popular contemporary books at the intersection of social behavior, psychology, and business, including The Tipping Point and Blink. Gladwell is a journalist and not a traditional scholar, but he is a well-known author and commentator on technical and intellectual topics whose readership cuts across the usual academic, intellectual, and business community boundaries. Like quantitative literacy, he is outside of the typical boxes.

The premise, and perhaps the conceit, of Mindware is found in the book's introduction: "The concepts in this book will show you how to think and act more effectively. The ideas provide a supplement to common sense - rules and principles you can learn to apply automatically and effortlessly to countless problems that crop up in everyday life" (4).

Let's dissect that quote to understand just how lofty the goal is. "Automatically and effortlessly"-wow! Those are two loaded words. So is the word "countless" and the phrase "everyday life." This has me wandering a land of hyperbole in a state of dubiousness.

In my view, smarter thinking is rarely effortless or automatic, unless perhaps you already have a base level of knowledge in the subject you're trying to be smarter in. The rules and principles referred to in the quote above are not conveyed in a convenient list or otherwise summarized. However, the concepts Nisbett chooses to write about are governed by the following attributes (11-12): The concepts have to be "important," "teachable," "form the core of systems of thought," and "can be triangulated to understand a given problem from many perspectives" (11-12).

I point these quotes out mostly to suggest that at times Nisbett writes like a professor at the blackboard who doesn't look around to see if the students are absorbing what he writes. If the quote above stopped at "supplement to common sense," I'd say the book achieves its mission.

For the numeracy and quantitative literacy community, however, the core value of Mindware lies in the middle chapters, especially chapter 11, "Eekonomics," in which Nisbett takes multiple regression analysis (MRA) to task. Here are the three main points, by his own listing:

- "Studies that rely on correlations to establish a scientific fact can be hopelessly misleading" (171).

- "Experiments in which people (or objects of any kind) are assigned randomly to one treatment versus another (or no treatment at all) are in general far superior to research based on MRA" (171). 
- "Assumptions are so often wrong when it comes to human behavior that it's essential to conduct experiments, if at all possible, to test any hypothesis about behavior that matters" (171).

He goes on to say later that "there are countless examples of MRA studies finding one thing and experiments finding another" (179).

According to Nisbett, the most frequent culprit leading to inaccuracy in MRA studies is errors based on self-selection. Many economists and social scientists are taught MRA as their "main statistical tool, but they are not taught to be nearly as critical of it as they need to be" (182). And Nisbett, a psychologist, admits that his "tribe" is as guilty of misusing MRA as other behavioral scientists.

Another critical point Nisbett makes is this: correlation doesn't prove causation. But worse, lack of correlation doesn't prove lack of causation. "False negative findings can occur using MRA just as false-positive findings do" (190).

A close reading of these middle chapters shows that Nisbett is advocating for competently conducted experiments where and whenever possible, instead of or to supplement MRA, rather than just trashing MRA. He also notes that MRA is useful in identifying relationships that would be important to subsequently examine experimentally.

However, it is also important to add that in other writings, Nisbett has come out more strongly against MRA, even producing an over 30-minute lecture titled "The Crusade Against Multiple Regression Analysis," reported by one source at the Edge website. ${ }^{1}$

Juxtaposing the following two examples in Mindware is perhaps a litmus test for determining whether Nisbett achieves his goal of rules and principles that you can apply automatically and effortlessly to think and act more effectively. On page 278, Nisbett cites a letter in The Wall Street Journal about changes in global temperatures as evidence for or against global warming. He urges readers to think about what the standard deviation might be for temperature changes from one year to another, which he states are "quite large actually." On page 281, he cites the near-universal consensus among climate experts that global climate change is occurring, due at least in part to human activities. Then he alludes to reporting that Fox News commentators have standing orders that anyone presenting this view must be rebutted by someone who denies the correctness of the consensus.

I've been evaluating the global climate change phenomenon and electricity industry contributions and solutions for several decades. I am also someone passionate about error analysis in any quantitative assessment. While it might be "automatic" for someone like me to think about standard deviations in temperature changes (and, I might add, measurement error in all techniques for monitoring or

\footnotetext{
1 https://www.edge.org/conversation/richard_nisbett-the-crusade-against-multiple-regression$\underline{\text { analysis }}$
} 
inferring temperature yesterday, a thousand years ago, and a million years ago), it certainly isn't going to be automatic for just about everyone else.

Of course, what the management at Fox and other cable news outlets knows is that the vast majority of the public makes little to no effort to be truly informed, or at least informed through multiple sources, and then consciously assess what they think they've learned. Most, in fact, don't possess the baseline knowledge to assess the results of scientific climate studies.

I'm not knocking anyone here. I don't have the baseline knowledge to know if a particular knee surgery is right for the level of pain I am experiencing, or for a thousand-and-one other subjects.

Fox News would of course argue that their viewers' perspective is tempered by a "balanced" debate. If those viewers don't make the follow-on effort to learn that the number of climate experts outside of the consensus is minuscule, then they will be misinformed.

In fact, I would argue that the more you know about error and bias and what I call the six Cs-co-location, coincidence, correlation, causation, convergence, and consensus - the greater effort you have to put in to decide what is a fact or "truth." Nisbett concedes this on page 258: "Deductive reasoning follows logical rules, producing conclusions that can't be refuted if the premises are correct. But most knowledge is obtained not by logic but buy collecting evidence."

That evidence has to support a theory or hypothesis, which has to be repeated by other researchers and validated by more evidence and experiments, and that information then has to converge and ultimately become a consensus among those who have the means to weigh in. This is how knowledge is constructed.

He notes later that the theory of evolution wins out over any other theory of the origin of life - of which there are only two others, namely creation by a god or gods and seeding by extraterrestrials. The same could be said for the Big Bang theory of the origin of the universe. The theory has big holes and gaps. Cosmologists continue to search for the evidence that will fill the gaps. Nevertheless, it is the theory that has the greatest consensus among experts at this time.

In the final chapter, "Conclusion: The Tools of the Lay Scientist," Nisbett delivers the good and bad news. The bad news is that "our beliefs about many important aspects of the world are often sorely mistaken and the ways in which we acquire [those beliefs] are often fundamentally flawed" (187). The good news is "you already knew you were fallible before you read the book. You now know much more about what produces your failings and how to compensate for them. This knowledge will help you perceive the world accurately and behave more sensibly" (275-276). 
In the final analysis, Mindware is an excellent treatment on how knowledge is constructed, written by a world-renowned psychologist. To boot, the illustrations of Nisbett's rules and principles go well beyond the realm of psychology.

In my opinion and experience, he stretches in claiming that his rules and principles could lead to effortless and automatic application. At best, that would depend entirely on the reader's background level of knowledge, analytical skills, and skepticism. At the risk of adding a subjective observation, nothing about doing research, thinking critically, or challenging accepted "knowledge" is effortless. These activities, instead, require a state of mind, active endeavor, and deliberate intention. It does, in fact, require endless effort. Further, it is uncomfortable, often deeply so. It is even more critical for students and teachers of QL to recognize these facts, because numbers in and of themselves make many people uncomfortable. However, I may be reading too much into this one word, or imbuing it with meaning Nisbett did not intend.

Any reader with a minimum level of reasoning ability, or just sheer curiosity, should find Mindware informative, useful, and engaging, even if its tone leans arrogant and its objectives overly ambitious.

Mindware's core value to the Numeracy community is the role it plays in Nisbett's crusade to rein in MRA and those who rely on it. It also contributes to the work of making MRA's limitations familiar to those who make decisions based on reported numerical results. In other words, all of us. As such, I hope it is finding its way into the canon for quantitative reasoning and literacy programs, and popularity with the lay public. 